\title{
Evaluating Impacts from Natural Weather-Related Disasters on Farmers Mental Health Worldwide
}

\author{
K. Palmer ${ }^{1}$, R. Strong ${ }^{2}$
}

\begin{abstract}
This study sought to assess the mental health impacts on farmers from across the globe post-natural weather-related disasters. There were two objectives that guided the study: (a) determine themes among the literature discussing post-disaster impacts on farmers' mental health, (b) identify personal characteristics that influence farmers' mental health post-disaster. A systematic review revealed $29(\mathrm{~N}=29)$ publications relevant to the research objectives. Through conducting an extensive systematic review six themes were identified: suicide, preparedness, culture, adaption, sentiment, and financial hardship. There were two personal characteristics presented in the literature: gender and age. It was indicated that farmers' perceptions of climate change affected their response to lessen emotional and physical impacts. The severity of the natural disaster played a role in the action farmers took to restore and prepare damages not only for the land but also regarding their mental health. Implications of this study uncovered an opportunity for extension personnel to create educational resources to combat mental health impacts from natural disasters. Recommendations include further research be conducted to investigate the effect of new or existing mental health resources on a sample of farmers from across the globe.
\end{abstract}

\section{Keywords}

Climate change, agricultural extension systems, resiliency, food security

1. Karissa Palmer, Graduate Research Fellow, Texas A\&M University, 600 John Kimbrough Blvd. Suite 233A College Station, TX. 77843-2116, karissa.palmer@ag.tamu.edu, (iD) https://orcid.org/0000-0003-3595-5213

2. Robert Strong, Associate Professor, Texas A\&M University, 600 John Kimbrough Blvd. Suite 267, College Station, TX. 778432116, robert.strongj@@ag.tamu.edu, (D) https://orcid.org/0000-0001-5279-4808 


\section{Introduction and Problem Statement}

With the impending food crisis to consider, farmers' resiliency to climate change needs to be a key attribute of sustainable agricultural systems (Rosin et al., 2013). Climate change is predicted to negatively impact the agricultural industry by affecting growth rates, crop productivity, photosynthesis, transpiration rates, and moisture (Mahato, 2014). Natural disasters are events with major consequences including heatwaves, landslides, droughts, forest fires, floods, tsunamis, and tropical cyclones (Sivakumar et al., 2005). Global occurrences of natural disasters began dramatically increasing in 2010 necessitating future study (Laframboise \& Loko, 2012).

Mental health problems following natural disaster occurrences include depression, posttraumatic stress disorder (PTSD), substance use, and anxiety (Simpson et al., 2011). The two most cited sources regarding the mental health of farmers are financial hardships and inconsistent climate change (Yazd et al., 2019). Farmer mental health will worsen as droughts become more severe due to climate change (Howard et al., 2020). Stakeholders experience difficulty with reaction to climate change due to the complexities and knowledge gaps in understanding the effects of climate-related disasters (Kiem \& Austin, 2013).

Societal issues and current demands underscore the necessity for extension systems agility to meet individual and community needs as a trusted source of information (Harder et al., 2013). Extension agents who are prepared and possess professional competencies have the potential to make positive impacts on food security (Ganpat et al., 2016; Strong \& Harder, 2011b). Extension agents need to develop the following competencies: communication skills, interpersonal skills, self-management, technical/subject matter expertise, program development process, and teaching abilities (Benge et al., 2011; Harder et al., 2009). Farmers are struggling with mental illness around the world and lack mental health care resources to improve their mental state (Ringgenberg et al., 2018).

\section{Theoretical and Conceptual Framework}

There were two theories used to frame this study the social cognitive theory (SCT) and resiliency theory. The SCT suggests the degree individuals attain and regulate their behavior through control and strengthening (Bandura, 1986). It is assumed through the SCT that environmental changes affect individuals. The SCT is concentrated on genetic and hormonal tendencies of learning that affect behavior.

According to SCT, there are six things that affect behavior: reciprocal determinism, behavioral capability, observational learning, reinforcements, expectations, and self-efficacy (Bandura, 1986). A person's behavior that influences and is influenced through social and external environments is reciprocal determinism (Bumguardner et al., 2014). Behavioral capability is a person's actual ability to execute a behavior through acquired knowledge (Bandura, 1986). The replication of behavior that was witnessed or observed by an individual is known as observational learning. Reinforcements are the internal or external responses to a person's 
behavior that influence the probability of continuing or discontinuing a behavior. Expectations are the anticipated outcomes of a person's behavior. Lastly, self-efficacy refers to an individual's confidence in their ability to perform a behavior (Bandura, 1986).

The resiliency theory concentrates on the positive contextual, social, and individual variables that interrupt the development of problem behaviors, poor mental and physical health, after experiencing trauma (Yeager \& Dweck, 2012). Opposing to risk factors there are encouragement factors which include positive social, contextual, and individual variables that help individuals overcome trauma. Assets are positive variables like self-efficacy and selfesteem that dwell within individuals. Resources are external variables including familial support, educational programs, and mentors that allow individuals to obtain information and apply the learned knowledge to their everyday lives. Contextual and organizational variables are offered through assets and resources, necessary for healthy improvement within individuals (Zimmerman, 2013).

\section{Purpose}

This international study sought to assess farmers' mental health post-natural weather-related disasters using SCT and resiliency theory. Identifying impacts from across the globe can help extension personnel better understand the detrimental effects of natural weather-related disasters on farmers' mental health, and thereby, offering agricultural extension programming opportunities to address farmer needs in preparation for future disasters. This study was guided by two objectives: (a) determine themes among the literature discussing post-disaster impacts on farmers' mental health, (b) identify personal characteristics that influence farmers' mental health post-disaster.

\section{Methods}

The mental health of farmers was assessed from 2010-2021 through the execution of a systematic review. Laframboise and Loko (2012) recommended the 2010 and beyond analysis due to the dramatic increase in the number of weather-related incidents in 2010 and 2011. Researchers are able to expand our existing knowledge by conducting an extensive literature review (Wright et al., 2007). A systematic review is a comprehensive review of existing literature to synthesize findings regarding the research question by following specific guidelines (Lee et al., 2021; Vindrola-Padros et al., 2021). The five steps to successfully complete a systematic review are: frame the question, identify relevant publications, assess study quality, summarize the evidence, and interpret findings (Khan et al., 2003). The question that guided the literature review was "how do natural weather-related disasters impact farmers' mental health?"

The researchers developed a list of keywords, step one, based on the literature and objectives of the study (Khan et al., 2003). The keywords were farmers and natural disasters, rural mental health, farmers and mental health, climate change and rural mental health, cooperative 
extension and climate change, cooperative extension and natural disasters, and farmer attitude and natural disaster. Researchers aimed to find relevant literature, step two, that focused on farmers' mental health after a natural disaster due to the changing climate using Google Scholar to search for journals with titles that included the respective keywords, and a Web of Science reported impact factor of 1 or higher. A list of literature was established that contained keywords in the title and body of the literature. The list was then sorted through to determine which articles were appropriate regarding the research question and current society. A total of $29(N=29)$ pieces of literature was discovered pertaining to the research objectives. There was a total of $27(n=27)$ journal articles analyzed from the systematic review parameters. The journal publications were from the following: American Journal of Public Health, Proceedings of the National Academy of Sciences of the United States of America, Journal of African Economies, Journal of Disaster Risk Reduction, Economics of Disasters and Climate Change, Climatic Change, Australasian Journal on Ageing, Economics and Management Australian Journal of Rural Health, Journal of Neurosciences in Rural Practice, Australian and New Zealand Journal of Public Health, Journal of Traumatic Stress, Sociologia Rurali, International Journal of Disaster Risk Reduction Social Science and Medicine, Canadian Journal of Counselling, International Journal of Environmental Research and Public Health, American Journal of Agricultural Economics, Agriculture, Indian Journal of Occupational and Environmental Medicine, Journal of Research in Commerce, and Journal of Rural Studies. A total of two books $(n=2)$ were reviewed: Natural Disaster System in China, and Rural mental health: Issues, policies, and best practices.

Step three (Khan et al., 2003), once an article was found, researchers determined if the article included keywords and included or excluded the publication from data analysis based upon: (a) the publication was peer reviewed; (b) keywords appeared in the title and throughout the article; and (c) the article must have been published between 2010 and 2021.

As identified by Khan et al.'s (2013) step four, the publications that included the keywords were then summarized into findings. For Khan et al.'s (2013) step five, the researchers identified six themes for objective one and two for themes for objective two based on the systematic review. Themes for both objectives were identified using the SCT and resiliency theory through analyzing farmers' behavior after natural weather-related disasters, by keeping in mind the variables that affect human behavior as mentioned previously. The summarized findings were organized depending on which theme they were a part of. Objective one themes were suicide, preparedness, culture, adaptation, sentiment, and financial hardship. Age and gender were the resulting themes of objective two. Researchers addressed trustworthiness of the data due to the frequency and number of themes produced from data analysis (Lincoln \& Guba, 1985) of the systematic review parameters.

Researchers collected data from studies around the world to assess commonalities between farmers (Wynn et al., 2013) from a variety of regions that experienced the effects from natural weather-related disasters and to ensure data transferability to similar contexts and populations (Khan et al., 2013; Lincoln \& Guba, 1985). There were seven countries that had literature discussing the mental health impacts on farmers post-disaster: Australia, Canada, China, Greece, India, Nigeria, and the United States. Limitations to this study are that the data does 
not allow for generalizability and only allows for conclusions to be drawn from the sample studied in each journal article. Researchers analyzed the data to determine whether the articles included relevant information. Texas A\&M University researchers determined the study was valid by assessing the criterion validity of the systematic review's procedures.

\section{Findings}

Researchers identified $29(\mathrm{~N}=29)$ scholarly publications that discussed farmers' mental health post-natural disasters and thus, aligned with the research objectives. The findings are organized by objective.

Objective one guided research to find recurring themes within the literature mentioning mental health affects post-natural weather-related disasters. Six $(n=6)$ themes identified from the literature: suicide, preparedness, culture, adaption, sentiment, and financial hardship. The themes are arranged below by starting with the topic that recurred the most.

\section{Suicide}

Areas with high levels of rural poverty tend to have more farmer suicides due to the occurrence of droughts and floods (Parida et al., 2018). In India, agriculture is reliant on the precipitation from monsoons, and a lack of monsoons leads to a series of droughts which increase farmer suicides (Singh., 2013). Suicide and depression have been linked with farmers being more worried about climate change (Ellis \& Albrecht, 2017). In Australia male farmers between 30 and 59 years, represent around $95 \%$ of rural suicides (Guiney, 2012). An effort to increase suicide literacy is a development known as SCARF (Suspect, Connect, Ask, Refer, Follow-Up) which is designed to improve the mental well-being of farmers (Perceval et al., 2020). Economic support and debt abolition were found to decrease farmer suicides as a result of climate change impacts (Padhy et al., 2015).

\section{Preparedness}

In a study assessing rural communities' preparedness levels, it was found that they demonstrate significantly lower preparedness in comparison to urban communities (Chai et al., 2021). Farmers are more likely to adopt earthquake disaster preparedness behaviors if they are trained in disaster prevention and mitigation (Lian et al., 2021). A study from Wenchuan and Lushan, two areas that have experienced severe earthquakes, found positive impacts on farmers' happiness, life satisfaction, and general health when they were prepared for the disaster (Qing et al., 2021). According to the results of a study after the 2013 floods in China, farmers from flooded villages are more likely to purchase index insurance (Liu et al., 2019). Farmers check the forecast 15-20 times a day during dry seasons due to their worries about the weather (Ellis \& Albrecht, 2017). Farmers are able to receive mental health care from their homes in Greece through a development known as Mobile Health Units (Peritogiannis et al., 2017). 


\section{Culture}

Due to China being the most populous country in the world, they are more likely to experience more frequent hazard impacts (Shi et al., 2016). Farmers' cultural characteristics are known to prevent them from seeking help and ignore their mental health (Vayro et al., 2020). In Greece, rural communities lack facilities and socioeconomic status which prevents them from being able to access mental health care (Peritogiannis et al., 2017). Farmers make up approximately $20 \%$ of the population in the United States who have limited access to mental health resources (Smalley et al., 2012). Due to the culturally inappropriate ways mental health services are provided, farmers resist the services because they do not want to be perceived as insane (Polain et al., 2011).

\section{Adaption}

In the United States Pacific Northwest, a study found no association between precipitation distributions and temperature change and a person's plan to adapt (Maas et al., 2020). Opposed to those who believe climate change is not a pressing issue, concerned farmers in lowa were more enthusiastic about mitigative and adaptive strategies (Arbuckle et al., 2013). Weather-related disasters are strongly affecting farmers in developing countries and when it comes to farm management measures there is a strong relationship between farmer characteristics and crop input (Huang et al., 2015).

\section{Sentiment}

Interconnections have been found between mental health and climate change including the connection farmers have with their farm and land, the personal significance of farms being like home, and climate change conditions affecting farmers' place-related mental health (Ellis \& Albrecht, 2017). In Australia, 5 years after a bushfire, it appeared that significant anger issues were found in farmers (Cowlishaw et al., 2021). Within 3 months of Hurricane Irma depression, anxiety, and physical pain were present in farmers from the United States (Grattan et al., 2020).

\section{Financial Hardship}

In China, land expropriation has negative impacts on the health of farmers who lost their land due to effects on income and protection for the long term (Wang et al., 2019). A study conducted on two rural counties in California indicated that mental health impacts were caused by finances and property (Barreau et al., 2017). Droughts and floods affect economic conditions along with agriculture production by damaging houses, crops, properties, and mental health (Parida et al., 2018).

The second objective determined the personal characteristics of farmers that impacted their mental health. Age and gender were the two personal characteristics produced from the systematic review.

\section{Age}

Young farmers or farmers with higher incomes are more likely to buy disaster insurance due to previous disaster experiences, feelings about disasters, or where they reside (Bao et al., 2021). A study indicated how younger farmers experiencing financial hardship and residing in remote 
areas are more likely to experience drought-related stress (Austin et al., 2018). In Nigeria, a study indicated that rainfall shocks impact child health significantly in the short run for weight and height, and height and age (Rabassa et al., 2014). Factors affecting the health of aging Australian farmers include respiratory disease, heat stress, solastalgia, financial hardship, mosquito-borne diseases, social networks, coastal regions, and remote communities (Horton et al., 2010). Due to long seasons of drought older farmers feel an immense sense of loss of success physical well-being, profit, community status, and relationships (Polain et al., 2011).

\section{Gender}

Women from 45-61 years are more able to cope with the impacts of drought without showing mental health effects in comparison to men (Powers et al., 2015). A major preventative for Manitoban male farmers is to have family support (Sturgeon \& Morrissette, 2010). Individuals who are unemployed, women, or younger in rural communities have higher aggression rates post-disaster (Cowlishaw et al., 2021). Male farmers and their families in Australia are more likely to be affected by droughts causing an increase in suicide (Hanigan et al., 2012).

\section{Conclusions, Discussion, and Recommendations}

Extension personnel should consider prioritizing suicide, culture, and preparedness as major topics to discuss due to the literature expressing their impacts frequently. Vulnerable populations who are more likely to experience mental illness found in the study include aging farmers, women, young farmers, and geographically worse rural communities. Mental health resources are available to farmers; however, they are less likely to want help, or they do not have access (Chai et al., 2021). In each country, there are different strategies implemented to prepare for disaster impacts. The literature presents an abundance of research regarding farmers' mental health in Australia, meaning mental health may be more of a concern there rather than in other countries. Natural disasters may occur more frequently in Australia and researchers may notice the mental health concern regarding farmers after a disaster in that country.

Farmers are more likely to seek help from their support system which relates to the reciprocal determinism concept (Bandura, 1986). Behavioral capability was presented through farmers' attitudes toward mitigating negative impacts and the potential for future climate changerelated disasters. The way farmers perceive climate change influences their response to mitigate future emotional and physical impacts (Bandura, 1986; Coppedge \& Strong, 2013). It can be inferred that the cultural characteristics of farmers would be more efficacious (Bandura, 1986; Wynn et al. 2013) in response, preparation, and recovery after a natural disaster.

Geographical locations that struggle with rural poverty experience more suicides meaning fewer programs focused on farmer resiliency post-disaster (Zimmerman, 2013). Global extension systems must play an active role in mitigating natural weather-related disaster impacts while keeping in mind the impending food crisis. Without the communication and strategic planning by extension systems, consumers would be unaware of the food security 
issue facing our world. The capacity of farmers and extension personnel needs to be enhanced to combat natural weather-related disaster impacts. More specifically, extension agents should undergo training to increase their competencies (Harder et al., 2013) about the mental health of farmers post-disaster. When farmers are experiencing good mental health food security is more likely to be achieved through resilient and sustainable agriculture. There is an abundance of existing literature that discusses the mental health of farmers; however, extension systems should continue researching to discover ways to improve rural mental health and mental health services available to farmers.

Research in the future should consist of an experimental design that investigates the effectiveness of a mental health program among a sample of farmers from around the world. In conducting an experiment, the results may reveal opportunities (Strong \& Harder, 2011a) for extension personnel to understand how to better prevent farmers from experiencing the stressors expressed in this study. Farmers' mental health is a global issue and a detriment to agricultural development. Health professionals and agricultural extension professionals from around the globe should collaborate and determine the best strategies for combating mental illness among farmers. Farmers' perceptions about climate change affect the likelihood of implementing successful adaptive strategies (Yeager \& Dweck, 2012). Disseminating accurate and accessible information is necessary for farmers to become motivated to adopt preventive strategies (Bandura, 1986) to combat mental illness.

The SCT and resiliency theory were useful in determining farmers' behavior regarding natural weather-related disasters and mental illness prevention. The findings indicated that farmers' behavior was influenced through their external environment, such as areas with higher levels of poverty (Parida et al., 2018), level of preparedness (Chai et al., 2021), lack of facilities and socioeconomic status (Peritogiannis et al., 2017), or prior disaster experience (Liu et al., 2019). It was also indicated that farmers' self-efficacy toward mental health care was low due to the abundance of suicide occurrences mentioned in the literature. Farmers are more resilient when trained in disaster prevention and mitigation (Lian et al., 2021) or when they were more concerned with the negative impacts from climate change (Arbuckle et al., 2013).

\section{Acknowledgements}

This study was supported by the USDA National Institute of Food and Agriculture's Hatch Project \#TEX09890 "The Adoption Impact of Food and Agricultural Sciences Curricula on Public Health." This respective Hatch Project and the research contained in this article aligns with the USDA Critical Issue "Connecting Agriculture and Health (1862)." The authors wish to express their gratitude to the USDA NIFA for supporting their research. 


\section{References}

Arbuckle, J. G., Morton, L. W., \& Hobbs, J. (2013). Farmer beliefs and concerns about climate change and attitudes toward adaptation and mitigation: Evidence from lowa. Climatic Change, 118(3-4), 551-563. https://doi.org/10.1007/s10584-013-0700-0

Austin, E. K., Handley, T., Kiem, A. S., Rich, J. L., Lewin, T. J., Askland, H. H., Askarimarnani, S. S., Perkins, D. A., \& Kelly, B. J. (2018). Drought-related stress among farmers: Findings from the Australian Rural Mental Health Study. The Medical Journal of Australia, 209(4), 159165. https://doi.org/10.5694/mja17.01200

Bandura, A. (1986). Social foundations of thought and action: A social cognitive theory. Prentice-Hall.

Bao, X., Zhang, F., Deng, X., \& Xu, D. (2021). Can trust motivate farmers to purchase natural disaster insurance? Evidence from earthquake-stricken areas of Sichuan, China. Agriculture, 11(8), 783. https://doi.org/10.3390/agriculture11080783

Barreau, T., Conway, D., Haught, K., Jackson, R., Kreutzer, R., Lockman, A., Minnick, S., Roisman, R., Rozell, D., Smorodinsky, S., Tafoya, D., \& Wilken, J. A. (2017). Physical, mental, and financial impacts from drought in two California counties, 2015. American Journal of Public Health, 107(5), 783-790. https://doi.org/10.2105/ajph.2017.303695

Benge, M., Harder, A., \& Carter, H. (2011). Necessary pre-entry competencies as perceived by Florida extension agents. Journal of Extension, 49(5), 1-11. https://archives.joe.org/joe/2011october/a2.php

Bumguardner, K. M., Strong, R., Murphrey, T. P., \& Dooley, L. M. (2014). Examining the blogging habits of agricultural leadership students: Understanding motivation, use, and selfefficacy. Journal of Agricultural Education, 55(3), 32-42. https://doi.org/10.5032/jae.2014.03032

Chai, L., Han, Y., Han, Z., Wei, J., \& Zhao, Y. (2021). Differences in disaster preparedness between urban and rural communities in China. International Journal of Disaster Risk Reduction, 53, 102020. https://doi.org/10.1016/j.ijdrr.2020.102020

Coppedge, R. H., \& Strong, R. (2013). Vocational programs in the Federal Bureau of Prisons: Examining the potential of agricultural education programs for prisoners. Journal of Agricultural Education, 54(3), 116-125. https://doi.org/10.5032/jae.2013.03116 
Cowlishaw, S., Metcalf, O., Varker, T., Stone, C., Molyneaux, R., Gibbs, L., Block, K., Harms, L., MacDougall, C., Gallagher, H.C., Bryant, R., Lawrence-Wood, E., Kellett, C., O'Donnell, M. \& Forbes, D. (2021). Anger dimensions and mental health following a disaster: Distribution and implications after a major bushfire. Journal of Traumatic Stress, 34(1), 46-55. https://doi.org/10.1002/jts.22616

Ellis, N. R., \& Albrecht, G. A. (2017). Climate change threats to family farmers' sense of place and mental wellbeing: A case study from the Western Australian Wheatbelt. Social Science \& Medicine, 175, 161-168. https://doi.org/10.1016/j.socscimed.2017.01.009

Ganpat, W. G., Ramjattan, J., \& Strong, R. (2016). Factors influencing self-efficacy and adoption of ICT dissemination tools by new extension officers. Journal of International Agricultural and Extension Education, 23(1), 1-13. https://doi.org/10.5191/jiaee.2016.23106

Grattan, L. M., Lindsay, A., Liang, Y., Kilmon, K. A., Cohen, S., Irani, T., \& Morris, J. G. (2020). The short-and long-term impacts of hurricane Irma on Florida agricultural Leaders as early emergency responders: The importance of workplace stability. International Journal of Environmental Research and Public Health, 17(3), 1050. https://doi.org/10.3390/ijerph17031050

Guiney, R. (2012). Farming suicides during the Victorian drought: 2001-2007. Australian Journal of Rural Health, 20(1), 11-15. https://doi.org/10.1111/j.1440-1584.2011.01244.x

Hanigan, I. C., Butler, C. D., Kokic, P. N., \& Hutchinson, M. F. (2012). Suicide and drought in New South Wales, Australia, 1970-2007. Proceedings of the National Academy of Sciences of the United States of America. 109(35), 13950-13955. https://doi.org/10.1073/pnas.1112965109

Harder, A., Ganpat, W. G., Moore, A., Strong, R., \& Lindner, J. R. (2013). An assessment of extension officers' self-perceived programming competencies in selected Caribbean Countries. Journal of International Agricultural and Extension Education, 20(1), 33-46. https://doi.org/10.5191/jiaee.2013.20103

Horton, G., Hanna, L., \& Kelly, B. (2010). Drought, drying and climate change: Emerging health issues for ageing Australians in rural areas. Australasian Journal on Ageing, 29(1), 2-7. https://doi.org/10.1111/i.1741-6612.2010.00424.x

Howard, M., Ahmed, S., Lachapelle, P., \& Schure, M. B. (2020). Farmer and rancher perceptions of climate change and their relationships with mental health. Journal of Rural Mental Health, 44(2), 87-95. https://doi.org/10.1037/rmh0000131 
Huang, J., Wang, Y., \& Wang, J. (2015). Farmers' adaptation to extreme weather events through farm management and its impacts on the mean and risk of rice yield in China. American Journal of Agricultural Economics, 97(2), 602-617. https://doi.org/10.1093/ajae/aav005

Khan, K. S., Kunz, R., Kleijnen, J., \& Antes, G. (2003). Five steps to conducting a systematic review. Journal of the Royal Society of Medicine, 96(3), 118-121. https://doi.org/10.1258/irsm.96.3.118

Kiem, A. S., \& Austin, E. K. (2013). Drought and the future of rural communities: Opportunities and challenges for climate change adaptation in regional Victoria, Australia. Global Environmental Change, 23(5), 1307-1316. https://doi.org/10.1016/i.gloenvcha.2013.06.003

Laframboise, N., \& Loko, B. (2012). Natural disasters: Mitigating impact, managing risks. International Monetary Fund Working Papers, 2012(245). 1-31. https://doi.org/10.5089/9781475512717.001

Lee, C. L., Strong, R., \& Dooley, K. E. (2021). Analyzing precision agriculture adoption across the globe: A systematic review of scholarship from 1999-2020. Sustainability, 13(18), 10295. https://doi.org/10.3390/su131810295

Lian, P., Zhuo, Z., Qi, Y., Xu, D., \& Deng, X. (2021). The impacts of training on farmers' preparedness behaviors of earthquake disaster-evidence from earthquake-prone settlements in rural China. Agriculture, 11(8), 726. https://doi.org/10.3390/agriculture11080726

Lincoln, Y. E., \& Guba, E. G. (1985). Naturalistic inquiry. Sage Publications. https://doi.org/10.1016/0147-1767(85)90062-8

Liu, X., Tang, Y., Ge, J., \& Miranda, M. J. (2019). Does experience with natural disasters affect willingness-to-pay for weather index insurance? Evidence from China. International Journal of Disaster Risk Reduction, 33, 33-43. https://doi.org/10.1016/j.ijdrr.2018.09.006

Maas, A., Wardropper, C., Roesch-McNally, G., \& Abatzoglou, J. (2020). A (mis) alignment of farmer experience and perceptions of climate change in the US inland Pacific Northwest. Climatic Change, 162(3), 1011-1029. https://doi.org/10.1007/s10584-020-02713-6

Mahato, A. (2014). Climate change and its impact on agriculture. International Journal of Scientific and Research Publications, 4(4), 1-6. https://www.nswai.org/docs/Climate change impact on Agriculture.pdf 
Padhy, S. K., Sarkar, S., Panigrahi, M., \& Paul, S. (2015). Mental health effects of climate change. Indian Journal of Occupational and Environmental Medicine, 19(1), 3-7. https://doi.org/10.4103/0019-5278.156997

Parida, Y., Dash, D. P., Bhardwaj, P., \& Chowdhury, J. R. (2018). Effects of drought and flood on farmer suicides in Indian States: An empirical analysis. Economics of Disasters and Climate Change, 2(2), 159-180. https://doi.org/10.1007/s41885-018-0023-8

Perceval, M., Reddy, P., Ross, V., Joiner, T., \& Kolves, K. (2020). Evaluation of the SCARF wellbeing and suicide prevention program for rural Australian communities. The Journal of Rural Health, 36(2), 247-254. https://doi.org/10.1111/jrh.12373

Peritogiannis, V., Manthopoulou, T., Gogou, A., \& Mavreas, V. (2017). Mental healthcare delivery in rural Greece: a 10-year account of a mobile mental health unit. Journal of Neurosciences in Rural Practice, 8(4), 556-561.

https://dx.doi.org/10.4103\%2Fjnrp.jnrp 142 17

Polain, J. D., Berry, H. L., \& Hoskin, J. O. (2011). Rapid change, climate adversity and the next 'big dry': Older farmers' mental health. The Australian Journal of Rural Health, 19(5), 239-243. https://doi.org/10.1111/j.1440-1584.2011.01219.x

Powers, J. R., Dobson, A. J., Berry, H. L., Graves, A. M., Hanigan, I. C., \& Loxton, D. (2015). Lack of association between drought and mental health in a cohort of 45-61 year old rural Australian women. Australian and New Zealand Journal of Public Health, 39(6), 518-523. https://doi.org/10.1111/1753-6405.12369

Qing, C., Guo, S., Deng, X., \& Xu, D. (2021). Farmers' disaster preparedness and quality of life in earthquake-prone areas: The mediating role of risk perception. International Journal of Disaster Risk Reduction, 59, 102252. https://doi.org/10.1016/j.ijdrr.2021.102252

Rabassa, M., Skoufias, E., \& Jacoby, H. (2014). Weather and child health in rural Nigeria. Journal of African Economies, 23(4), 464-492. https://doi.org/10.1093/jae/eju005

Ringgenberg, W., Peek-Asa, C., Donham, K., \& Ramirez, M. (2018). Trends and characteristics of occupational suicide and homicide in farmers and agricultural workers, 1992-2010. The Journal of Rural Health, 34(3), 246-253. https://doi.org/10.1111/irh.12245

Rosin, C., Stock, P., \& Campbell, H. (2013). Food systems failure: The global food crisis and the future of agriculture. Routledge. https://doi.org/10.4324/9781849776820

Shi, P., Xu, W., \& Wang, J. A. (2016). Natural disaster system in China. Springer Publishing. https://doi.org/10.1007/978-3-662-50270-9 1 
Simpson, D.M., Weissbecker, I., \& Sephton, S.E. (2011). Extreme weather-related events: Implications for mental health and well-being. Springer Publishing. https://doi.org/10.1007/978-1-4419-9742-5 4

Singh, J. (2013). Analytical study of farmer suicide in Indian agriculture sector. International Journal of Research in Commerce, Economics and Management, 3(6), 58-65. https://ijrcm.org.in/article info.php?article id=3394

Sivakumar, M. V. K., Motha, R. P., \& Das, H. P. (Eds.). (2005). Natural disaster and extreme events in agriculture. Springer Publishing. https://doi.org/10.1007/3-540-28307-2

Smalley, B. K., Warren, J. C., \& Rainer, J. (Eds.). (2012). Rural mental health: Issues, policies, and best practices. Springer Publishing.

Strong, R., \& Harder, A. (2011a). The effects of Florida Master Gardener characteristics and motivations on program participation. Journal of Extension, 49(5). https://archives.joe.org/joe/2011october

Strong, R., \& Harder, A. (2011b). Recommended competencies needed for teaching in international extension settings. Journal of International Agricultural and Extension Education, 18(3), 72-83. https://doi.org/10.5191/jiaee.2011.18306

Sturgeon, R., \& Morrissette, P. J. (2010). A qualitative analysis of suicide ideation among Manitoban farmers. Canadian Journal of Counselling and Psychotherapy, 44(2), 191207. https://cjc-rcc.ucalgary.ca/article/view/59003

Vayro, C., Brownlow, C., Ireland, M., \& March, S. (2020). 'Farming is not just an occupation [but] a whole lifestyle': A qualitative examination of lifestyle and cultural factors affecting mental health help-seeking in Australian farmers. Sociologia Ruralis, 60(1), 151-173. https://doi.org/10.1111/soru.12274

Vindrola-Padros, C., Brage, E., \& Johnson, G. A. (2021). Rapid, responsive, and relevant?: A systematic review of rapid evaluations in health care. American Journal of Evaluation, 42(1), 13-27. https://doi.org/10.1177\%2F1098214019886914

Wang, Y., Li, W., Xiong, J., Li, Y., \& Wu, H. (2019). Effect of land expropriation on land-lost farmers' health: Empirical evidence from rural China. International Journal of Environmental Research and Public Health, 16(16), 2934. https://doi.org/10.3390/ijerph16162934

Wright, R. W., Brand, R. A., Dunn, W., \& Spindler, K. P. (2007). How to write a systematic review. Clinical Orthopaedics and Related Research, 455, 23-29. https://doi.org/10.1097/BLO.0b013e31802c9098 
Wynn, J. T., Coppedge, R. H., \& Strong, R. (2013). Future IPM trends in Trinidad and Tobago: A qualitative study of farmers' perspectives. Journal of International Agricultural and Extension Education, 20(2), 65-76. https://doi.org/10.5191/jiaee.2013.20205

Yazd, S. D, \& Wheeler, S. A., \& Zuo, A. (2019). Key risk factors affecting farmers' mental health: A systematic review. International Journal of Environmental Research and Public Health, 16(23), 4849. https://doi.org/10.3390/ijerph16234849

Yeager, D. S., \& Dweck, C. S. (2012). Mindsets that promote resilience: When students believe that personal characteristics can be developed. Educational Psychologist, 47(4), 302314. https://doi.org/10.1080/00461520.2012.722805

Zimmerman, M. A. (2013). Resiliency theory: A strengths-based approach to research and practice for adolescent health. Health Education and Behavior, 40(4), 381-383. https://doi.org/10.1177/1090198113493782

(c) 2022 by authors. This article is an open access article distributed under the terms and conditions of the Creative Commons Attribution license (http://creativecommons.org/licenses/by/4.0/). 